\title{
The Cameroon Academy of Sciences Model of Evidence-based Science Advice
}

\author{
David A. Mbah ${ }^{1 *}$, Samuel N. Ayonghe ${ }^{1}$, Vincent N. Tanya ${ }^{1}$, Vincent P. K. Titanji ${ }^{1}$, Magellan \\ Guewo-Fokeng ${ }^{2}$ \\ ${ }^{1}$ Cameroon Academy of Sciences, P.O. BOX 1457 Yaoundé, Cameroon \\ ${ }^{2}$ Post-Doctoral Intern, Cameroon Academy of Sciences, P.O. BOX 1457 Yaoundé, Cameroon \\ *Corresponding author: David A. Mbah: dambah@yahoo.co.uk
}

\begin{abstract}
The evidence-based science advice (ESA) effort of the Cameroon Academy of Sciences (CAS) since 23 years has been reviewed. The objective throughout has been to enable science influence policy/decision making at all levels - national, regional and global. The key partners of CAS included the United States National Academy of Sciences (USNAS), the German Academy of Sciences (Leopoldina), the Royal Society of United Kingdom, as well as the Network of African Science Academies (NASAC), the InterAcademy Partnership (Science, Health, Research), the Commonwealth Science Academies and the International Science Council. The mechanisms used included consensus studies, workshops, public lectures, participation in sectoral committees, summaries of key scientific publications and joint statements. Priorities handled through convening activities were triggered by policy/decision making sector requests or Academy foresights. The response/impact of the effort varied from media coverage through policy/programme change/orientation. The major challenges faced included insufficient financial/human resources, inadequate office space, and weak links with government. These challenges must be addressed to enable effective evidence-based science advice which is increasingly unavoidable for sustainable development.
\end{abstract}

Keywords: Evidence-based science, advice, policy, decision-maker

\section{Résumé}

Les efforts de l'Académie des Sciences du Cameroun en matière de conseil basés sur des évidences scientifiques depuis 23 ans ont été passés en revue. L'objectif a toujours été de permettre à la science d'influencer la politique / la prise de décision à tous les niveaux - national, régional et mondial. L'Académie Nationale des Sciences des États-Unis, l'Académie Allemande des sciences Léopoldina, la Royal Society UK, le Réseau des Académies Africaines des Sciences, le Partenariat InterAcademy (Science, Santé, Recherche) et les Académies Scientifiques du Commonwealth ont été et continuent d'être les principaux partenaires. Les mécanismes utilisés comprenaient des études de consensus, des ateliers, des conférences publiques, la participation à des comités sectoriels, des résumés de publications scientifiques clés et des déclarations communes. Les priorités prises en charge par les activités de convocation ont été déclenchées par une demande du secteur de la politique / prise de décision ou par la prévoyance de l'Académie. La réaction / l'impact de l'effort variait d'une couverture médiatique à une orientation / un changement de politique / programme. Les principaux défis à relever étaient l'insuffisance des ressources financières et humaines, l'espace de bureau insuffisant et la faiblesse des liens avec le gouvernement. Ces défis doivent être relevés pour permettre un avis scientifique efficace, fondé sur des preuves, de plus en plus indispensable pour le développement durable.

Mots Clés : Evidence scientifique, Conseil, politique, décision.

Received: 22/10/2019

Accepted: 04/12/2019

DOI: https//dx.doi.org/10.4314/jcas.v15i2.4

(C) The Authors. This work is licensed under the Creative Commons Attribution 4.0 International Licence. 


\section{Introduction}

"Science is critical to narrowing the gap between developed and developing countries....This is why we have established the Rwanda Academy of Science to promote and support the role of science in sustainable development and to provide evidence-based solutions to leaders at all levels"((Rwandan President Paul Kagame, (2016) (Speaking for all Presidents?)).

Science Academies, Universities, Research Institutes, Inter-ministerial Committees, Consultants and more, serve as advisory bodies to national governments, national and international organizations and corporations. The quality/rigour of advice from these bodies is not the same. By virtue of their nature and characteristics, science academies are in a position to provide more robust advice. What follows is derived from presentations by Chumbow (2008), and Mbah (2008, 2009, 2011) during Annual Meetings of the African Science Academy Development Initiative and edited by Mbah D. A. (2015).

The Concept of Evidence-based Science Advice/ Virtues of Science Academy Advice are founded on six major pillars:

i) Core values governing the activities of the Academy, which usually include independence; relevance, integrity, objectivity, and quality;

ii) Design of the study within the niche of the Academies or other learned bodies;

iii) Quality and diversity of experts involved in the study. Typically, experts on the study committee represent multidisciplinary, national and international mix, gender sensitivity, expertise (qualification, experience);

iv) Absence of conflict of interest;

v) Process of delivery: This usually includes a study/report review (team of reviewers that includes national and international experts, speakers and non-speakers of the study, an overviewer to coordinate integration of reviewers' comments into the report and gender balance). The output is usually a consensus study report based on evidence.

vi) The Academy usually possesses a level of public confidence and acceptance that the advisory study can command. This depends very much on points i-v above.
Given this foundation, Science Academy Advice in general and that of the Cameroon Academy of Sciences in particular, differs from that of advisory bodies such as universities, research institutes, inter-ministerial committees, team of consultants, etc, by:

1. Being strictly evidence-based,

2. Respecting the core values of the Academy while advice from other bodies has no set of core values to refer to,

3. Being broad-based while that from other bodies is usually within the narrow mandates of such bodies (ministries, institutes, etc.), and

4. Being independent.

Governments usually turn to inter-ministerial committees, however. Advice from interministerial committees has its insufficiency given that:

1.The composition of committees is generally not determined by merit/technical expertise but by administrative position/political affiliation which at times, may be of very low level,

2. Participation at times tends to defend positions of ministries rather than the facts as revealed by evidence,

3. The resulting report is not a result of a rigorous process characterized by: a) Multidisciplinary, b) Committee composition based on a set of rigorous criteria, c). Review and overview of the report and d) Independence. Conflicts of interest can easily interfere with non-Academy Science Advice given that the experts are employees or contractors of the user organization. Given this situation, other departments of government in particular, and the public in general, may reject in various ways the advice/report. This can happen often in a multiparty situation. Hence, it is advisable that governments (decision markers) seek Science Academy Advice if general ministerial and public acceptance of decisions on difficult or controversial issues is desirable. 
I. Foundations of Science Advice

The pillars of any merit-based science academy include link with government, vision, mission and core values. For the Cameroon Academy of Sciences, these are as follows:

\section{a) Link with government/policy making} sector

- Recommendation (of National Council for Higher Education and Scientific and Technical Research sessions of 1974 and 1982 presided over by then President of the Republic of Cameroon, Ahmadou Ahidjo) that an academy of sciences be created for the country.

- The foundation of the Cameroon Academy of Sciences happened in November 1990 in Douala under the inspiration of African Academy of Sciences,

- The ratification of decision of Douala group by Constituent Assembly in January 1991 Adoption of draft statutes of the Academy,

- Formal recognition in May 1991 in accordance with law no. 90/053 of 19 December 1990 regulating freedom of association,

- Inauguration by the Prime Minister, Mr. Simon Acbidi Acbu, 10 February 1993,

- The Academy (represented by former President of the Academy, Prof. Victor Anomah Ngu) signed a protocol of collaboration with the Ministry of Scientific and Technical Research (Prof. Henri Hogbe Nlend) on the $4^{\text {th }}$ May 2001.

\section{b) Vision}

- The Cameroon Academy of Sciences is to be the prime mover of science and technology - synthesis of scientific knowledge and making it available to decision and policy makers about investments and priorities in science and technology, and promoting the use of science and innovation in the economic, social and cultural development of Cameroon.

\section{c) Mission}

- The mission of the Cameroon Academy of Sciences is to promote excellence and relevance in science and technology and to provide advice to the government.

- The Academy produces robust forum and committee advisory documents and reports on priority problems and issues and delivers them to policy and decision makers and the public.

- The independence, highly qualified membership, multidisciplinary composition, and rigorous procedures for objective and unbiased analysis enable the Academy to effectively deliver credible advice.

\section{d) Core Values}

The following are the core values important to the Cameroon Academy of Sciences:

- Quality of fellowship, products, and so on;

- Objectivity of documents, reports, and opinions;

- Integrity of documents, reports, and opinions supported by evidence;

- Independence from pressure groups - public or private; and

- Relevance to the problems of the society.

\section{e) Main Goal of the Academy}

The main goal of the Academy is to promote the progress of science, technology, and innovation for the economic, social, and cultural development of Cameroon.

\section{f) Standing Fora}

A forum is a convening activity bringing stakeholders together to prioritize themes of engagement for a given period. Typically, it consists of experts, policymakers, and NGOs (national and international), The objective is to establish priorities. Planning committees would follow for each theme at implementation period.

So far existing fora include:

- Forum on Food Security;

- Forum on Public Health; 
- Forum on Climate Change; and

- Forum on Science Education (in process)

The Objective of each forum is prioritization of areas/themes for CAS engagements.

\section{g) Specific objectives of the Academy}

- Promoting research and technological training at the highest level;

- Advising the national government and other national and international policy makers; on issues related to science and technology in the service of man;

- Popularizing science and technology culture;

- Contributing to the defense of science and the franchise of scientists;

- Developing scientific and technological relations with the private and public sectors of the national economy; and

- Promoting scientific and technological cooperation at the international level.

Given its service function, the Academy is currently structured into three Colleges, comprising 87 Fellows/Associate Fellows, 1 Honorary, 11 Women: Head of State is Protector of the Academy. The three colleges of CAS are the:

College of Biological Sciences (35 Fellows),

- College of Mathematics and Physical Sciences (27 Fellows), and

○ College of Social Sciences (25 Fellows).

\section{Science Advice}

Mechanisms/approaches of Evidence based Science Advice (ESA or EBSA): modus operandi

The Cameroon Academy of Sciences has 6 major mechanisms/approaches to enable science advice: "Science Academy - Policymaker interaction for Evidence-Based Decision Making" (CAS, 2007).
The advice is triggered by either a request by sector/user or fore sighting by the Academy / group of Academics.

1) Consensus Studies: These are analytical studies conducted by a multidisciplinary team/group of experts and submitted to rigorous review process. It represents the position of the Academy. It has the following characteristics:

a) Design of study within the niche of the Academy,

b) Quality and diversity of experts. Typically, experts on study committee reflect:

- multidisciplinary,

- national and international mix,

- gender sensitivity, and

- absence of conflict of interest.

c) Process of delivery of study: Under Coordination of Executive Secretariat, the delivery is characterized as follows:

- study team (national and international), multidisciplinary,

- study review team (national, international) and gender sensitive,

- study overview,

- CAS branding of report, and

- dissemination of study.

So far five consensus studies have been effected. Three of these were outputs of partnership with US National Academy of Sciences, one from partnership with the German Academy of Science Leopoldina/NASAC and one with partnership with Bioresources Development and Conservation Programme Cameroon (BDCPC)British High Commission.

Note: Report represents opinion of the Academy.

2 Workshops: modus operandi: Under Coordination of Executive Secretariat, each workshop is characterized as follows:

- Multidisciplinary Planning Committee of Experts, 
- Policymaker(s) from sector Ministry in Planning Committee,

- Trust building.

Speakers: these are commissioned on the basis of expertise:

- policymaker(s),

- experts/researchers, scientists,

- Science writer to produce report,

- Report review team national/international,

- Speakers and non-speakers,

- Report overviewer,

- CAS branding of report, and

- Dissemination of workshop report.

Twelve workshops were realized. Five of these resulted from partnership with the US National Academy of Sciences while two resulted from partnership with Leopoldina/NASAC and one from partnership with IAP/NASAC.

Note: Opinions in report are those of the speakers. Participants return with new ideas about their work.

3 Public Lectures: modus operandi: Under the Coordination of the Executive Secretariat, each lecture is usually characterized as follows:

- $\quad$ Speakers (experts) and discussants,

- Participants:

- Targeted policy sectors,

○ Members of Parliament (MP), and

○ Media (written, electronic).

There were four public lectures on hepatitis, prostate disease, distant education, HIV/AIDS vaccine discovery effort, and climate change.

Case of public lecture on climate change:

1) A Member of Parliament: "I have understood only about $25 \%$ of the presentations. Can you make a simplified presentation to the National Assembly (MPs)?”

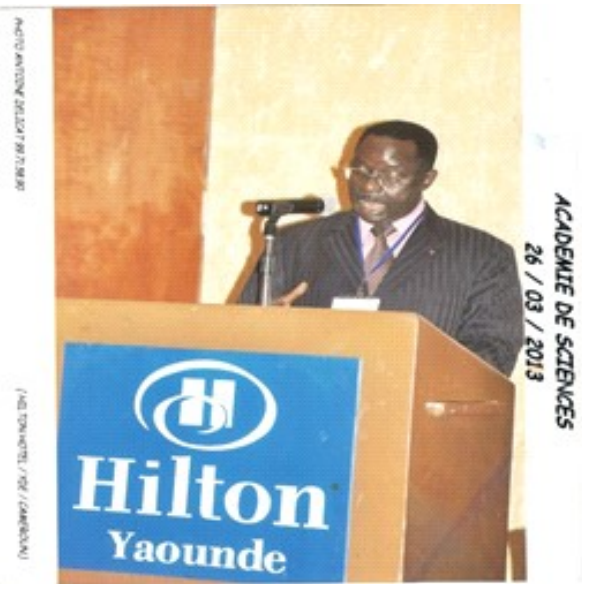

2) Results/Response to the question:

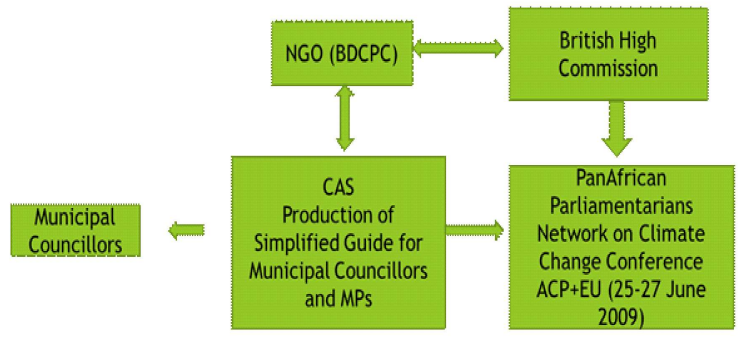

3) Summaries of selected articles from the Journal of the Cameroon Academy of Sciences (JCAS) in particular for the attention of targeted sectors: modus operandi: Executive Secretariat produces summary with the following:

- $\quad$ English version,

- $\quad$ French version, and

- Coordinates of the corresponding author (for details that the targeted policymaking sector may desire). 
4). Major publications: Journal, consensus studies, theses, workshops:

Journal of the Cameroon Academy of Sciences
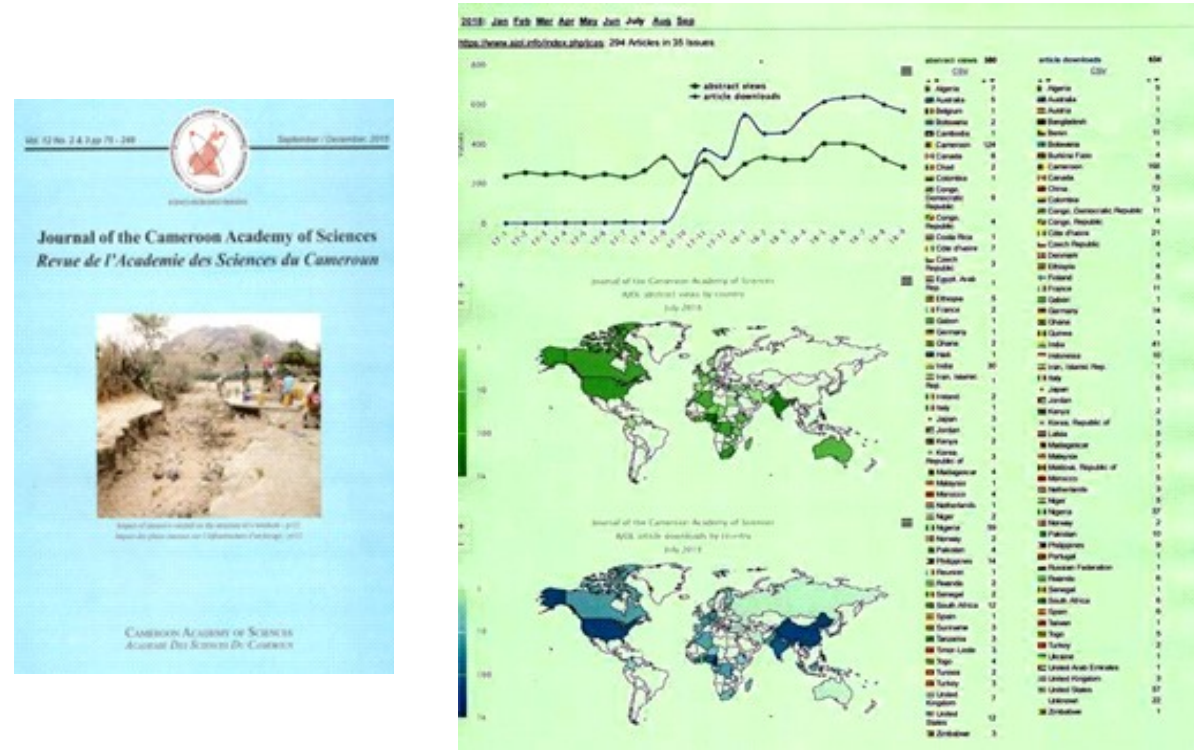

5) Some Workshop and Consensus Study Reports (http://www.casciences.org, P.O. Box 1457, Yaounde):
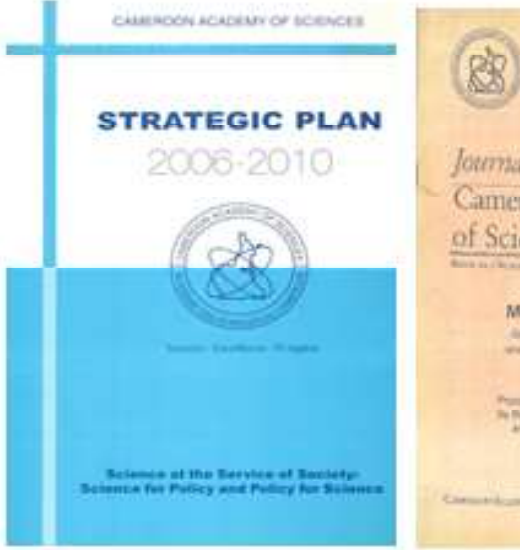

Joumalof the

GameroonAcademy

of Sciences
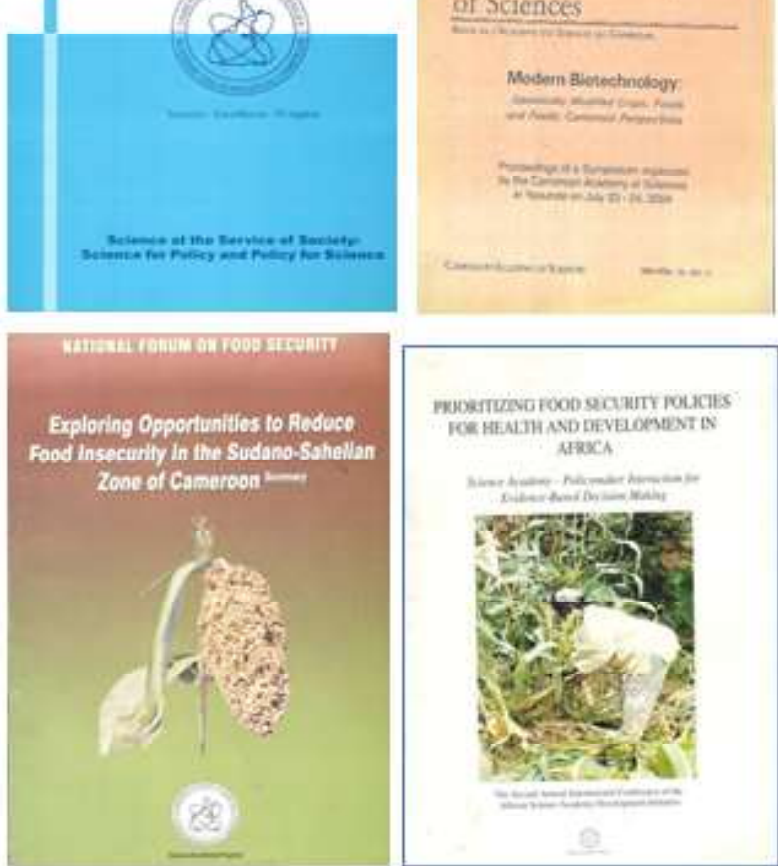
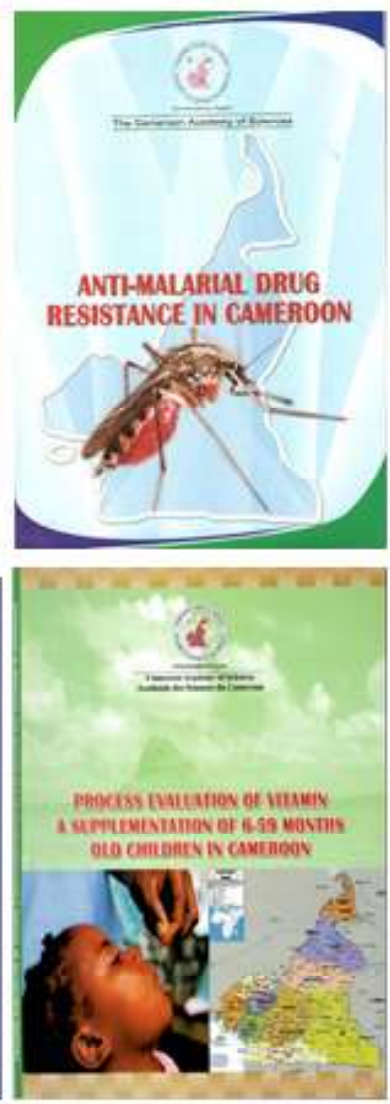

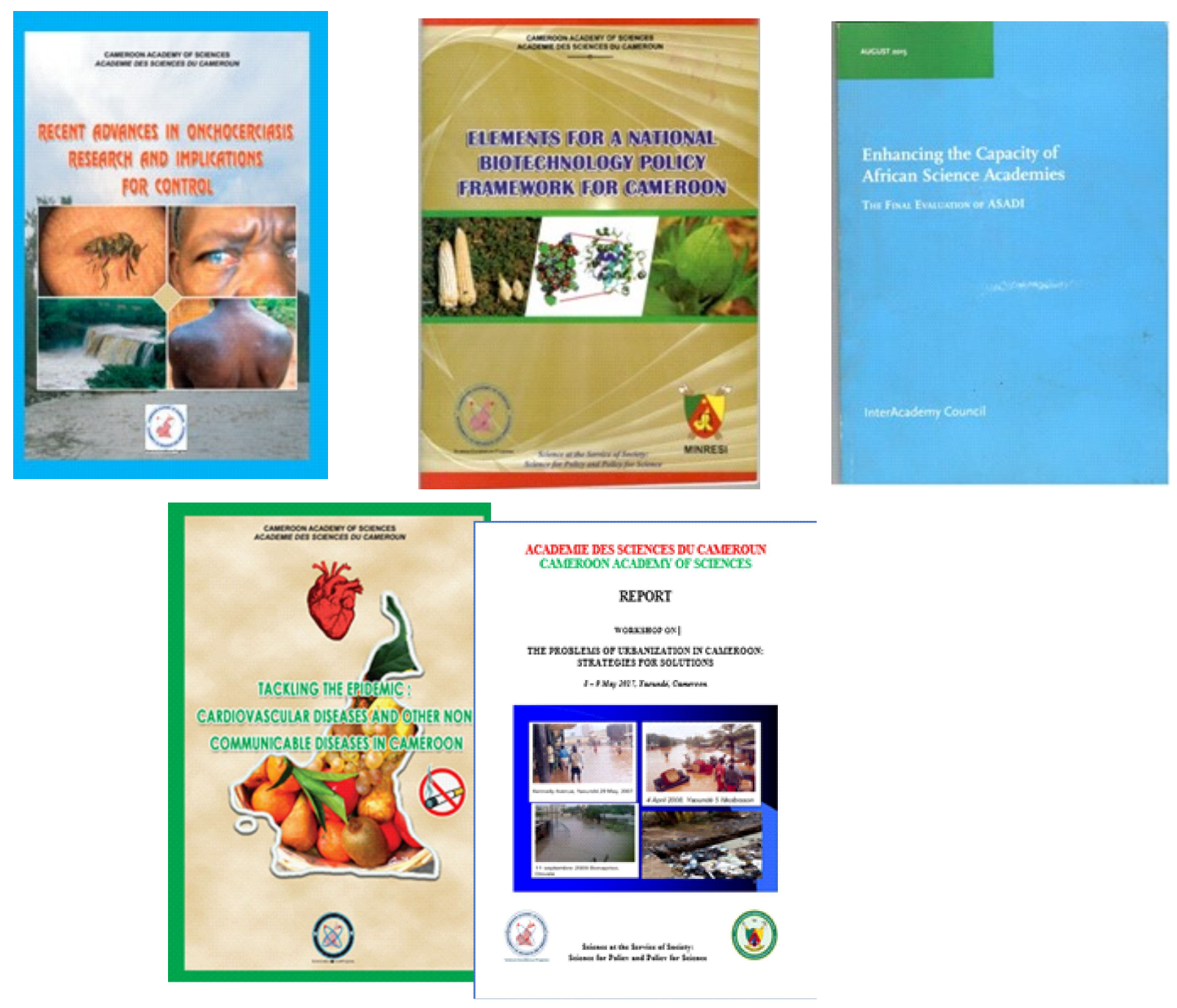

6) CAS fellows' presence on committees: modus operandi

- Designation based on expertise, and

- Contribution(s) respect core values of CAS.

7) Statements: positions of science academies on national, regional or global issues for the attention of national governments, regional organizations and the United Nations.: modus operandi

- Drafting group made of key national and regional academies;

- Draft statement submitted to member academies for inputs/suggestions as may be necessary;

- Final version signed by participating academies (at least $50 \%$ of member academies must have signed before it becomes a position statement of the Academies).

- $\quad$ Launching of statement by all academies on same date. The launching format is adapted for the needs of each member academy.

The Cameroon Academy of Sciences has such statements with the Network of African Science Academies (NASAC), the InterAcadeemy Patnership (Health, Science, Research) and the Commonwealth Science Academies including the Network of Commonwealth Science Advisers (NCSA). 
III. Responses to Science Advice Received: Over time, the Cameroon Academy of Sciences has received written responses to its Science Advice as follows:

- Written response: Office of Prime Minister/ Head of Government, Ministry of Environment and Nature Protection, Ministry of Higher Education, Ministry of Scientific Research and Innovation, Ministry of Finance

- Action(s)/decisions taken: Ministry of Agriculture and Rural Development, Ministry of Public Health, Ministry of Environment Nature Protection and Sustainable Development,

- Policy/programme change: Ministry of Agriculture and Rural Development, Ministry of Public Health, Ministry of Scientific Research and Innovation.

Specifically:

1. Forum on food security in the sudano-sahalian region of Cameroon led to a national programme on food Security (IAC, 2014).

2. Combatting Cameroon's nutrition and health crisis led to the launching of a new food fortification programme supported by UNICEF (IAC, 2014).

3. Consensus study on onchocerciasis research and implications for control has been claimed in Cameroon and beyond and has influenced control strategies (IAC, 2014).

4. Strategic plan lead by CAS has been adopted by Cameroonians Higher Education (University of Buea, University of Yaoundé 1, University of Dschang, etc) (IAC, 2014).

5. Climate change and adaptation strategies outputs led to the establishment of the National Observatory for Climate Change (ONACC) and the creation of a Climate Change Laboratory at the University of Buea.
6. Journal of the Cameroon Academy of Sciences articles are accessed/downloaded in more than 56 countries including Europe and United States of America.

7. Climate change public lecture led to creation of new partnership with non-governmental organization (BDCPC), national assembly (Pan African Parliamentarians Network on Climate Change) and Diplomatic Missions (British High Commission, Konrad Ardenauer Foundation).

8. Workshop on urbanization: problems and strategies for solutions led to establishment of work partnership with the Ministry in charge of Housing and Urban Development.

\section{CAS on Ministerial Committees:}

The Cameroon Academy of Sciences has sometimes been invited to send experts to sit on various technical committees in government ministries.

Notably:

- Platform on Biodiversity Ecosystem Service: science - policy interface within Ministry of Environment Nature Protection and Sustainable Development,

- Week of excellence in Scientific Research and Innovation within Ministry of Scientific Research and Innovation,

- Ethics Committee within Ministry of Scientific Research and Innovation,

- Scientific convocation of the Ministry of Scientific Research and Innovation.

\section{Challenges}

Over the years the Academy encountered and continues to encounter challenges. These include inadequate funding/financial resources, insufficiency of 
office space, insufficient staff, and weak link with government/policy making sector.

\section{Conclusion}

The Cameroon Academy of Sciences uses multiple mechanisms/approaches for science advice. These approaches include consensus studies, workshops, public lectures, research (articles, theses, etc.) summaries, presence on sectoral committees and statements.

While consensus study reports represent the opinion of the Academy on a problem, workshop reports represent the opinions of the experts. Workshop participants return with new ideas about their work.

Statements represent the position of the Academy, African Science Academies (NASAC Statements), and Science Academies worldwide (IAP Statements).

Four of the advisory activities were REQUESTED while the rest (majority) were results of CAS FORESIGHTING. Trust building is part of the process of delivery.

Response to science advice is varied from decision/policy/programme change to modification in way of doing things.

The academy continues to seek stronger links with the government/policy making sector.

\section{Authors' contributions}

Conception: David A. Mbah, Samuel N. Ayonghe, Vincent N. Tanya,

Study design and first draft: David A. Mbah

Data collection: David A. Mbah, Magellan Guewo-Fokeng and Vincent N. Tanya, Review inputs: David A. Mbah, Magellan GuewoFokeng, Samuel N. Ayonghe and Vincent P. K. Titanji

Critical discussion and manuscript revision for intellectual content: David A. Mbah, Samuel N. Ayonghe, Vincent N. Tanya, Vincent P. K. Titanji All the authors approved the final version of the manuscript.
Conflict of interest - None

Source of funding - Work in the Cameroon Academy of Sciences is supported by individual members contributions and a grant-in-aid from the Ministry of Scientific Research and Innovation of Cameroon and international partners.

\section{Acknowledgements}

The special efforts of successive Ministers in charge of Science, Technology and Innovation: Dr. Jacob Ayuk Takem; Professor Henri Hogbe Nlend; Mr Zacharie Perevet and Dr. Madeleine Tchuinte. These Ministers, with successive Presidents of the Academy, late Professors Marc Bopelet, Victor Anomah Ngu and Domngang Samuel as well as former Executive Secretary, Prof. Paul N. Nkwi, worked to make evidencebased science advice a reality in Cameroon.

We further acknowledge the efforts of our external partners, United States National Academy of Sciences; Royal Society (UK) and German National Academy of Sciences Leopoldina, Network of African Science Academies and Konrad Ardenauer Foundation.

\section{References}

Chumbow S. B. 2008. Fitting Science into

Policy: Recent Experience of the Cameroon Academy of Sciences - Joint Lea4rning Session for the Annual Meeting of the African Science Academy Development Initiative (ASADI) sharing best practices and lessons learned, Royal Society, UK.

CAS. 2007. Prioritizing Food Security Policies for Health and Development in Africa: Science Academy - Policymaker Interaction for EvidenceBased Decision Making, 86pp

IAC. 2014.Final Evaluation of the African Science Academy development Initiative.

Mbah D. A. 2008. Science Academies as Partners for Improving the Impacts of Policies in Africa: Process and Values of Academy Work: Virtues of Academy Advice. Annual Meeting of the 
African Science Academy Development Initiative (ASADI), Royal Society, UK.

Mbah D. A. 2009. The Role of African Science Academies in Influencing Policy; In; The African Science Academy Development Initiative: Progress and Promise. The National Academies, Washington, Page 24.

Mbah D. A. 2011. Leveraging African Science Academies for Development Effectiveness. $7^{\text {th }}$ Annual Meeting of African Science Academies, Kampala, Uganda.

Mbah D.A. 2015. Science Academies: Process and Values of Academy Work Virtues of Academy Advice. JCAS 12: VII - VIII

Rwandan President Paul Kagame's speech at the $17^{\text {th }}$ TWAS General Assembly. https://twas.org 